\section{The next generation of scanners and imaging systems}

Align Technology, Inc. has announced the availability of the iTero Element Plus Series, which expands the company's portfolio of iTero Element scanners and imaging systems to include new solutions that serve a broader range of the dental market.

The new iTero Element Plus Series of scanners and imaging systems builds on the success of the award-winning iTero Element family and offers all of the existing orthodontic and restorative digital capabilities doctors have come to rely on - plus faster processing time and advanced visualisation capabilities for a seamless scanning experience in a new sleek, ergonomically designed package. Available in both cart and mobile configurations, the iTero Element Plus Series offers increased flexibility and mobility. The mobile configuration makes the power of the iTero Element Plus Series portable with a medical grade, compact mobile scanner solution that delivers

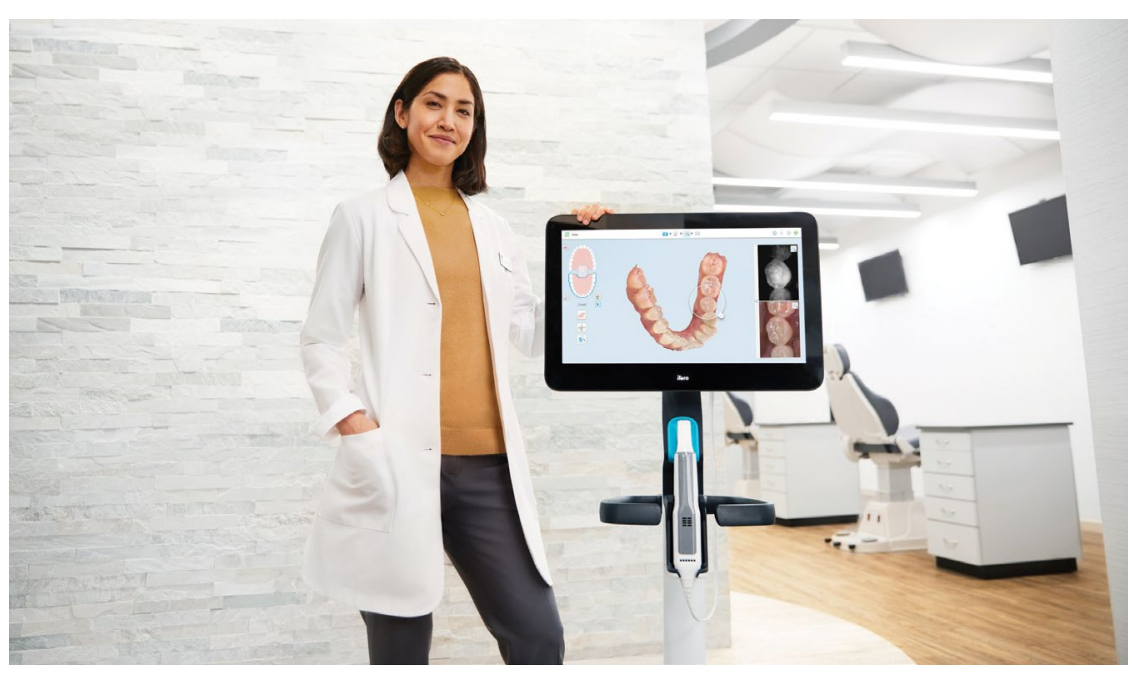

\section{The art of quality at your fingertips}

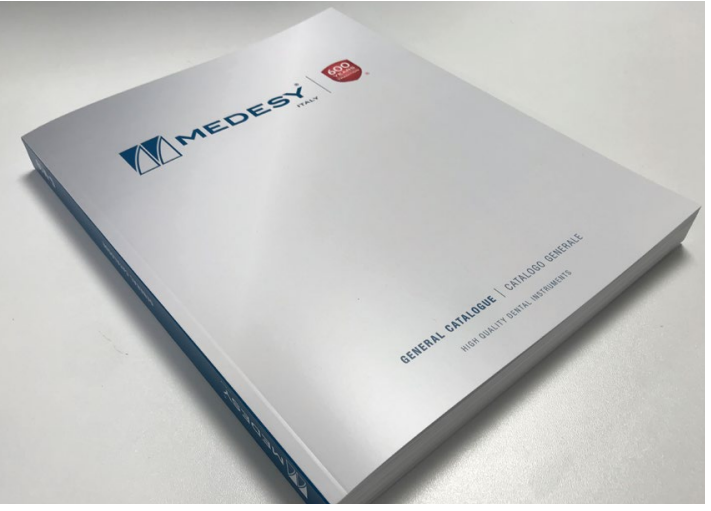

For over 600 years, Italian-based Medesy has been supplying dental instruments of unrivalled quality, supporting clinicians in achieving outstanding results for their patients.

Quintess Denta offers the full Medesy product range to dentists in the UK and Ireland - an incredible 3,000 items steeped in a long history of excellence.

Within the ranges available are tools for diagnostics, periodontal care, surgical treatment, orthodontics, restorative work and implantology. Myriad accessories are
Alternative business funding

\section{for dental practices}

Many small to medium sized businesses, particularly in dentistry, have needed extra support regarding cashflow to keep their doors from closing permanently during the pandemic.

Small businesses are increasingly looking to 365 Business Finance for flexible finance to help them, with the average merchant cash advance being slightly higher now than in previous years, at $£ 20,000$, up $10 \%$ in the last 12 months.

In addition, 365 Business Finance - a

London-based lender - has reported that they are now getting more merchant cash advance enquiries from businesses that have already taken government loans via the Bounce Back Loan Scheme (BBLS) and Coronavirus Business Interruption Loan Scheme (CBILS).

With a merchant cash advance, funding between $£ 5,000$ and $£ 200,000$ is still available even if a business has accessed BBLS or CBILS government support. The benefits include no APRs or fixed monthly payments.

To find out how businesses can survive the pandemic in 2021 with the current range of business funding options available to them, read 365 Business Finance's guide - which examines and compares the government schemes and grants on offer in the UK, as well as detailing how a merchant cash advance is an alternative or additional finance option for dental practices.

https://www.365businessfinance.co.uk/ blog/2021/01/12/planning-2021-whatfinancial-support-available-businesses/

also available, as are lab-focused items. In addition, bespoke kits can be made to order, fulfilling your needs to a tee.

Encompassing six centuries of Maniago blacksmiths' expertise, this market leader's prestigious, certified, stainless steel instruments are streets ahead of the competition.

For further information, contact Ian Creighton on +353 (0)16918870, email ian@ quintessdenta.com or visit quintessdenta. com/pages/medesy-navigation. 